\title{
Effect of Temperature on the Mechanical Properties of Unsaturated Polyester Reinforced with Fibers and Nanoparticles
}

Najah Rustum Mohsin

Southern Technical University (STU), Iraq, najahr2000@ stu.edu.iq

\begin{abstract}
A composite material is a material that consists of a matrix (base phase) and a stiffener (reinforcement) that combined together to build up a structural unit. Reinforcement material form may be fibers, flakes or as a particle. In the current paper, unsaturated polyester resin (UP) was used as a base material, Sisal fibers (SF), glass fibers (GF) and Silica dioxide $\left(\mathrm{SiO}_{2}\right)$ particles were performed as a reinforcing material. Three composite types were prepared: (C1) UP only, (C2) UP reinforced with $15 \% \mathrm{SF}$ and $15 \% \mathrm{GF}$, and (C3) UP reinforced with $15 \% \mathrm{SF}$ and $15 \% \mathrm{SiO}_{2}$ to investigate the effect of reinforcement type on some mechanical properties such as elastic modulus, compressive strength, hardness and impact toughness with various temperatures.

The experimental results showed that the mechanical properties of composite materials were improved by using reinforcement with fibers and nanoparticles. The high values of elasticity, hardness and toughness were obtained with the specimen C2 composite. While the highest values of compressive strength were obtained with the specimen C3.

On the other hand, the modulus of elasticity, compressive strength and hardness were decreased with increasing of temperature values with various percentages. Other clockwise, the toughness values were increased.
\end{abstract}

Keywords: Composite, Unsaturated polyester, Mechanical properties, Reinforcement

\section{Introduction}

The science of polymers has witnessed a great development in recent years due to its mechanical and chemical properties that made it compete with traditional materials in various fields. The world witnessed the beginnings of technical leaps in this field by the scientist (Staundinger) in (1920 AD) who laid the polymers science basics by assuming the hypothesis of large particles. Research and studies on these materials have continued rapidly to produce many types of industrial polymers and formulations prepared from them [1].

Can be defined as a composite material as a mixture of two (or more) substances that produces better properties than the properties of its individual components used [2]. It consists of: (i) a continuous phase (matrix), (ii) discontinuous phase, including particles and fibers (reinforcements), (iii) the interface, it express to the bounding surface between a matrix and reinforcement. Sharp or gradual discontinuity across the interface may take place, then the bonded between the reinforcement and the matrix should be well $[\mathbf{1 , 3}, \mathbf{4}]$.

Composite materials are characterized by high corrosion resistance, light weight, and good flexibility in machining, but they are less strong compared to some metals [5]. We can classify it according to matrix materials as $[6,7]$ : (i) Polymer composites: It consists of thermosetting or thermoplastic as a matrix with an Industrial or natural reinforcements, such as glass, sisal, carbon, etc. It has a good mechanical characteristics and many features such as a Lightweight, high strength, good fatigue properties and compression ability. Widely used in aircraft applications and sports equipment. (ii) Ceramic composites: it is a mixture of fibers, bristles and ceramic Particles with another ceramic matrix. Metals, ceramics, and polymers may be used as reinforcement in it. It has a high melting point, stability at high temperatures, 
corrosion resistance, and excellent compressive strength. Due to its special properties, it is preferred to use in high temperature applications such as blades, pistons and some parts of gas turbine [8]. (iii) Metal composites: It recognized as advanced materials. Metal composites represent composite materials with a pure metal or alloy basis reinforced with fibers, particles or filaments. It has excellent mechanical and thermal properties such as thermal conductivity and a wear resistance is very good $[9,10]$.

Particles and fibers are added to the resins to improve some mechanical properties. It may be synthetic or natural and their properties such as shape, size, distribution, fiber length and diameter, type of fibrils or particles and volume fraction are affected on the properties of the composite material $[\mathbf{1 1}, \mathbf{1 2}]$.

In the current paper, UP resin was reinforced with $\mathrm{SF}, \mathrm{GF}$ and $\mathrm{SiO}_{2}$ partials to investigate the effect of types of reinforcement, volume fraction and temperature on modulus of elasticity, compressive strength, hardness and toughness.

\section{EXPERIMENTAL PROCEDURE}

\subsection{Material}

UP resin (manufactured by Saudi SIR) was used to provide the samples. It is a thermosetting material in the form of a transparent liquid with a strong and distinctive smell. Methyl ethyl ketone peroxide was used as a hardened material. The resin turns into a solid state after adding the hardener. The mixing ratio of the hardener material was $(2: 100)$ to obtain the matrix. SF is a natural fiber and is characterized by its cheap price, availability and possession of superior mechanical properties. Previously it was widely used in the manufacture of ropes and carpets, but now it has become one of the most important reinforcements used in the composite materials. GF is the most popular used material in the field of polymeric materials. It used in the form of short hairs, braid, mat, fabric or in the form of powder. In current research, E-glass type fibers were used as a reinforcement material. Continuous fibers are woven into 2D layered arrays to provide strength in two axes. Table (1) shows some mechanical properties of Up, SF and $\mathrm{GF}_{\mathrm{E}}$.

Table 1 Properties of the samples contents [3, $13,14]$

\begin{tabular}{|c|c|c|c|c|}
\hline $\begin{array}{c}\text { Nam } \\
\mathrm{e}\end{array}$ & $\begin{array}{c}\text { Densit } \\
\left(\mathrm{g} / \mathrm{cm}^{3}\right. \\
)\end{array}$ & $\begin{array}{c}\text { Elong } \\
(\%)\end{array}$ & $\begin{array}{c}\text { Tensile } \\
\text { Strength } \\
(\mathrm{Mpa})\end{array}$ & $\begin{array}{c}\text { Modulus } \\
\text { of } \\
\text { elasticit } \\
\mathrm{y}(\mathrm{Gpa})\end{array}$ \\
\hline $\mathrm{UP}$ & 1.1 & 2.0 & $34-105$ & $2.1-3.5$ \\
\hline $\mathrm{SF}$ & 1.5 & $\begin{array}{c}2.0- \\
2.5\end{array}$ & $\begin{array}{c}511- \\
635\end{array}$ & $22-94$ \\
\hline $\mathrm{GF}_{\mathrm{E}}$ & 2.5 & 2.5 & $\begin{array}{c}2000- \\
3500\end{array}$ & 70.0 \\
\hline
\end{tabular}

$\mathrm{SiO}_{2}$ with various particle sizes (50-100) $\mu \mathrm{m}$ were used as filler materials, It is characterized by high stability, good mechanical and chemical properties, good resistance to acid and base solutions. Silica exists in three crystalline phases, quartz, tridymite and crystalline. The crystalline phase was performed in the current paper which was characterized by its high stability, Density is $2.2 \mathrm{~g} / \mathrm{cm}^{3}$ and thermal expansion is $10.3\left(10^{-6} \mathrm{~K}^{-1}\right)$.

\subsection{Sample preparation}

\subsubsection{Create the casting mold}

Glass slates with a dimension $(25 \times 25 \mathrm{~cm})$ and thickness of $(6 \mathrm{~mm})$ were used with a wax material to avoid sticking to the mold.

\subsubsection{Prepare the samples}

1) Preparation of unreinforced composite (C1): a quantity of UP is weighed according to the size of the designed molds and the hardener was added with $2 \%$.

2) Preparing composite was reinforced with sisal and glass fiber (C2):

The SF and GF mat were cut with dimensions of $25 \mathrm{~cm} \times 25 \mathrm{~cm}$ and weighed to achieving the volume fraction of $15 \%$ for each one. After that, they were placed in the electric dryer at $50 \mathrm{C}^{\mathrm{O}}$ for 10 Minutes to remove any moisture from 
them to prevent forming a separating surface between the base material and the support material, after that, arranging of the fibers was taking place in the mold in a successive (reciprocal) layer system (i.e. Glass - sisal - glass - sisal) and pouring the resin material over it so that it Homogeneous distributed in the mold.

3) Preparing composite reinforced by $S F$ and $\mathrm{SiO} 2(\mathrm{C} 3)$ :

a quantity of $\mathrm{SiO}_{2}$ was weighed at a rate of $15 \%$. Mixing process with UP by using a magnetic mixer was performed for an hour at room temperature to separate the particles from each other, as it is known that nanoparticles tend to clump due to their high surface area, so the separation of these particles from each other needs a longer time than larger size particles. After that, the hardener is added and mixed for 2 minutes. SF mat was cut with dimensions of 25 $\mathrm{cm} \times 25 \mathrm{~cm}$ and weighed to achieving the volume fraction of $15 \%$. Then, a process of pouring of the resin material was carried out so that it was distributed uniformly in the mold.

4) The casting process was left in the mold for period of (24) hours in order to harden permanently before being removed from it. Figures (1) and (2) show the three prepared samples and the microscopic pictures for them.

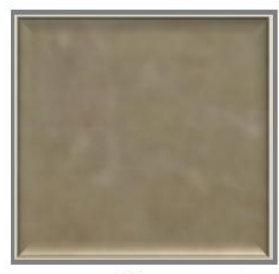

C1

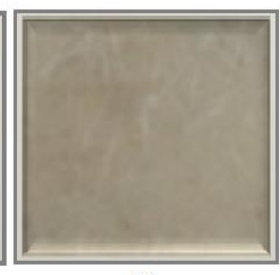

C2

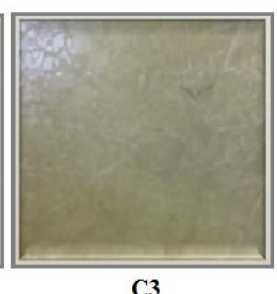

Fig. 1 The three samples that prepared in the current paper

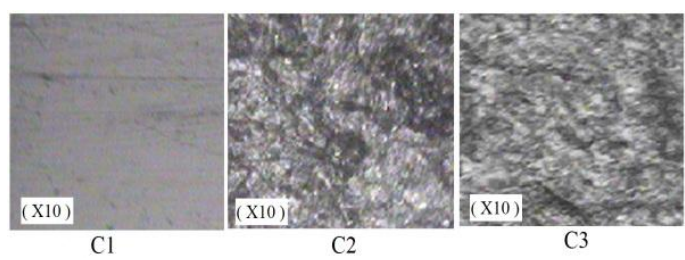

Fig. 2 the microscopic pictures for the prepared samples
Samples were cut according to standard dimensions of American specifications (ASTMD 790-1984) for each examination. Hand lay-up procedure was used to prepare the samples. A sensitive balance with accuracy 0.0001 was performed in this research. Volume fraction (V) was calculated by the following equation:

$$
\begin{aligned}
& \mathrm{V}_{\mathrm{m}}=\Psi_{\mathrm{m}} /\left(\Psi_{\mathrm{m}}+\Psi_{\mathrm{r}}\right) \\
& \mathrm{V}_{\mathrm{r}}=\Psi_{\mathrm{r}} /\left(\Psi_{\mathrm{m}}+\Psi_{\mathrm{r}}\right) \\
& \mathrm{V}_{\mathrm{m}}+\mathrm{V}_{\mathrm{r}}=1
\end{aligned}
$$

Where $\mathrm{V}, \Psi$ represent volume fraction, volume respectively, and the subscripts $\mathrm{m}, \mathrm{r}$, represent the matrix and the reinforcement components. Table (2) shows the details of the

\begin{tabular}{|c|c|c|c|}
\hline Symbols type & $\mathrm{C} 1$ & $\mathrm{C} 2$ & C3 \\
\hline $\begin{array}{r}\text { Reinforcement } \\
\text { weight }(\mathrm{g})\end{array}$ & 0 & $\begin{array}{c}4.5 \mathrm{SF} \\
\& 4.5 \\
\mathrm{GF}\end{array}$ & $\begin{array}{c}4.5 \mathrm{SF} \\
\& 4.5 \\
\mathrm{SiO}_{2}\end{array}$ \\
\hline $\mathrm{UP}(\mathrm{g})$ & 30 & 21 & 21 \\
\hline $\begin{array}{r}\text { Total Weight } \\
(\mathrm{g})\end{array}$ & 30 & 30 & 30 \\
\hline Total Vr \% & 0 & 30 & 30 \\
\hline Total Vm \% & 100 & 70 & 70 \\
\hline
\end{tabular}
sample contents.

Table 2 Details of the samples contents

\section{RESULT AND DISCUSSION}

One disadvantage of polymers is that they behave elastic at high temperatures and brittle at low temperatures. These properties can be improved by adding fibers and particles.

\subsection{Effect of Temperature on Modulus of elasticity}

Three point test device type Tinus Olsen /England (figure (3)) was used to calculate the elastic modulus.

\subsubsection{Cutting the samples}




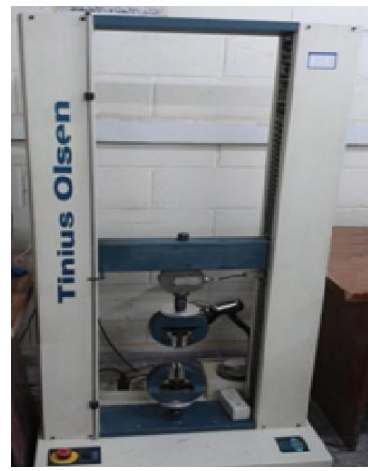

Fig. 3 Elastic modulus testing device

Figure (4) shows the relationship between modulus of elasticity (E) and temperature for all samples of models (C1, C2 and C3). It can be observed that, the modulus of elasticity was improved by adding fiber and particles to the mixture due to applied stress to the composite material was distributed over each of the matrix, fibers and particles. On the other hand, the modulus of elasticity values was decreased when increasing the temperature due to relaxation in the base material polymeric bonds accompanied by large strain rates.

It can be discovered that, the largest modulus of elasticity values was obtained by $\mathrm{C} 2$ model due to presence fibers leads to increase in bending modulus of elasticity and bearing the tensile strength, while in the third model $\mathrm{C} 3$, the presence of $\mathrm{SiO} 2$ particles lead to the emergence of primary cracks in or around the particles as a result of some contractions that may occur, these cracks will be reduce the modulus of elasticity because it was not transfer the stresses.

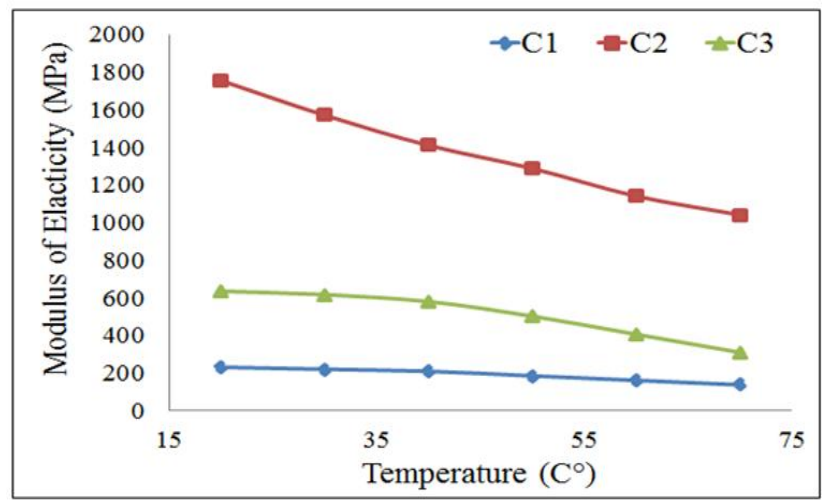

Fig. 4 Effect of temperature on modulus of elasticity
Hydraulic press Ley Bold Harris No.36110 (figure (5)) was performed to calculate the compressive strength.

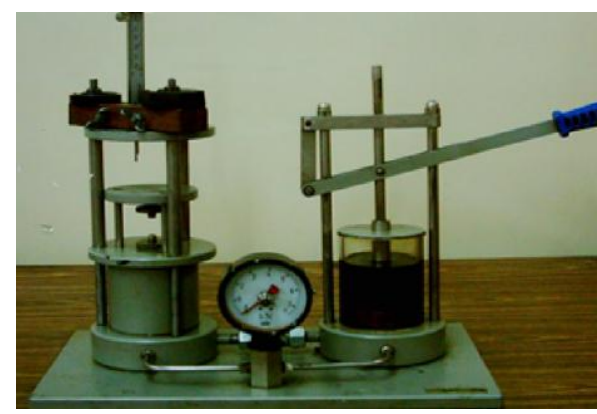

Fig. 5 Compressive strength testing device

Thermosetting resins (such as polyesters) have high compressive strength compared to tensile strength. The compressive strength in the longitudinal direction (parallel to the fibers) depends on the matrix and reinforcement material properties and the amount of volume fraction of each one and also depends on the amount of bonding force across the interfaces.

Figure (6) shows the relation between temperature and compressive strength. the compressive strength of $\mathrm{C} 3$ was greater than that of $\mathrm{C} 2$, which in turn is greater than that of $\mathrm{C} 1$, fibers will bear most of imposed stresses of the composite, but they do not prevent or hinder the emergence of longitudinal defects, those defects that arise near the loading area and which tend to move in a parallel direction to fibers, while the particles act as obstacles to crack growth and the occurrence of failure.

Other side, when the temperature increased, the compressive strength decreased, due to it causes weakening in the base material and interface bond force.

\subsection{Effect of Temperature on Compressive Strength}




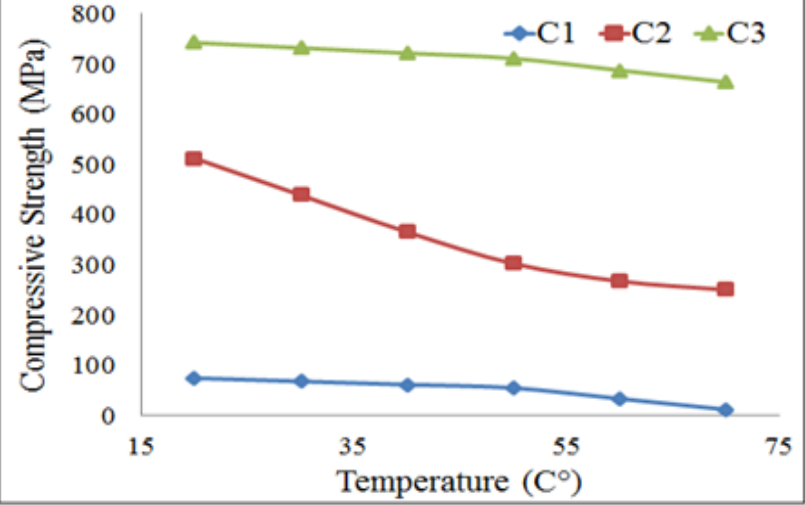

Fig. 6 Effect of temperature on compressive strength

\subsection{Effect of Temperature on Hardness}

Materials hardness depends on many factors such as: type of bonding force between its molecules or atoms, type of surface, temperature degree, etc. Hardness tests are based on the penetration resistance basis of the material surface and can be calculated for Brinell method by using the equation:

$$
H B=\frac{2 F}{\pi D\left(D-\sqrt{D^{2}-d^{2}}\right.}
$$

Where: F: applied load (N), D: Ball diameter $(\mathrm{mm}), \mathrm{d}$ : impression diameter $(\mathrm{mm})$.

Figure (7) shows the relation between temperature and Brinell hardness. It can be seen, when the reinforcement process was used, then the hardness value was increased. It can be observed that the reinforcement with fibers (model C2) leads to a large increase in the hardness values of the composite at the stability of the volume fraction. Reinforcement with sisal fibers and silicon partials (model C2) was led to improve the hardness values, but to a lesser extent. This confirms the positive effect of fiber reinforcement to improve the composite material hardness and it was indicated that the direct relation between hardness values and fiber enforcement layers when the total volume fraction was fixed.

On the other hand, the hardness values of all models were decreased with the increasing of the temperature value as a result of decreasing in the bonding forces between the molecules which makes the material ductile and reduces the surface resistance of the composite.

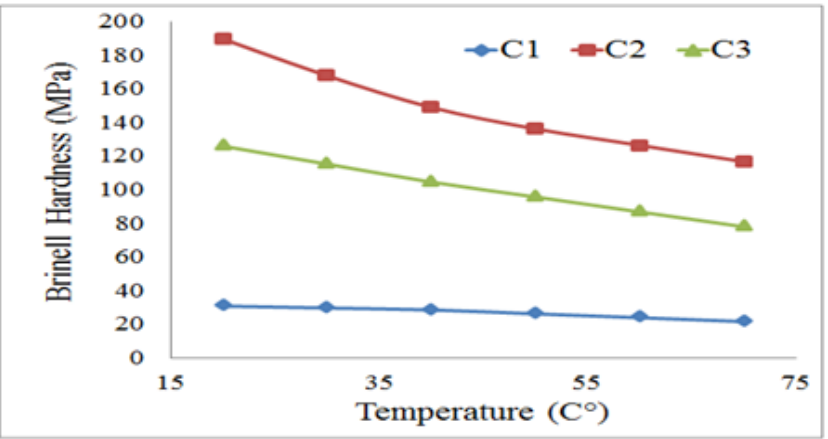

Fig. 7 Effect of temperature on Brinell hardness

\subsection{Effect of Temperature on Impact Toughness}

Toughness can be defined as the material's ability to absorb energy. It can be calculated by the following equation:

$$
E=P L(\cos \beta-\cos \alpha)
$$

Where: E: the energy required to break the sample, P: pendulum weight, L: pendulum length, $\alpha$ : pendulum angle before the sample is broken, $\beta$ : pendulum angle after the sample is broken. The device Testing Machines INC. and New AMITYVILLE, New York, Testing Machines INC. (figure (8)) was used to measure impact toughness /Charpy method.

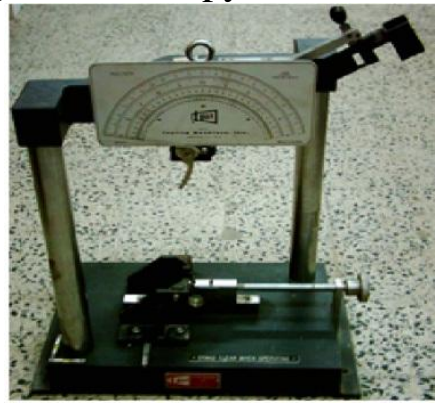

Fig. 8 Impact toughness testing device

From Figure (9) shows the relation between temperature and impact toughness. It can be seen that the impact toughness was increased significantly with reinforced by fibers due to it was carried out as obstacle to prevent the fracture. Otherwise, break strength was decreased by adding $\mathrm{SiO}_{2}$ particles to the fiber reinforcement due to it was as a stress concentration, then the fracture strength was 
decreased. Based on the results above, break depends mainly on the type, strength and direction of the fibers used in the base material because it will be an obstacle to fracture and will absorb most of the impact energy. The relatively rough surface of the fibers causes an increase in the bonding force between the fiber and the matrix, which in turn requires additional energy to pull the fibers out of the matrix, and this explains the role of the fibers in the fracture behavior. The fracture energy was improved when composite temperature increased due to increase its ductility and particle movement, the bonds become more elastic state therefore the impact toughness was increased.

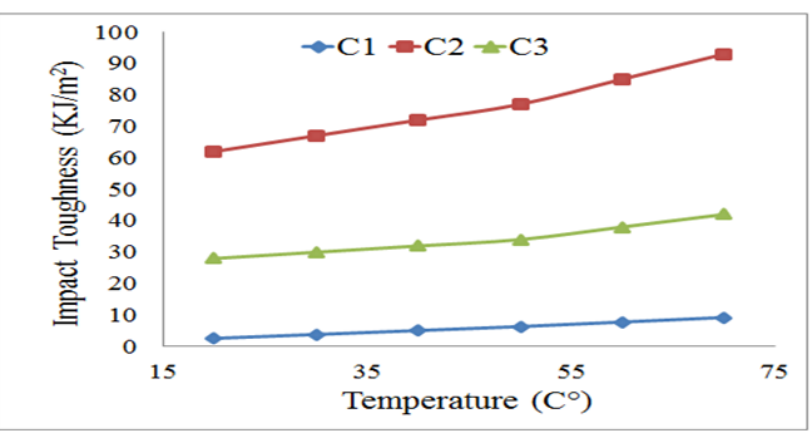

Fig. 9 Effect of temperature on impact toughness 4. CONCLUSIONS

Based on the experimental results, the reinforcement by fibers and nanoparticles was improved the mechanical properties of the composite with varying temperature. The biggest values of modulus of elasticity, hardness and Toughness were obtained by using sisal and glass fibers as a reinforcement, While the highest values of compressive strength was obtained by using sisal fibers and $\mathrm{SiO}_{2}$ particles. On the other hand, the modulus of elasticity, hardness, and tensile strength were decreased with increasing of temperature values, while impact toughness value was increased.

\section{ACKNOWLEDGEMENTS}

I would like to extend my sincere thanks to the employees of the laboratories of Al- Nasiriya Technical Institute / Southern Technical University / Iraq for their help to me to complete this paper.

\section{REFERENCES}

[1] K. K. Chawla, " Composite materials: science and engineering", Springer, New York, 2012.

[2] F.C. Campbell, "Structural Composite Materials", ASM International, 2010.

[3] T. D. Ngo, "Composite and Nano composite Materials", Knowledge to Industrial Applications, 2020.

[4] P. K. Mallick, " Advanced materials for automotive applications: An overview", Elsevier, 2012.

[5] A. S. Mahdi, N. R. Mohsin, "Water absorption and fatigue life of an Epoxy composite reinforced by glass fiber", Materials Science and Engineering, 2018.

[6] D. B. Miracle, S. L. Donaldson,"Composites", ASM International Handbook Committee, 21, 2001.

[7] A. K. Sharma, R. Bhandari, A. Aherwar, R. Rimasauskiene, "Matrix materials used in composites: A comprehensive study", 21, 15591562, 2020.

[8] A.K. Bhargava, "Engineering Materials: Polymers, Ceramics and Composites", PHI Learning Pvt. Ltd., New Delhi, India, 2010.

[9] B. Cantor, F.P.E. Dunne, I. C. Stone, "Metal and Ceramic Matrix Composites", CRC Press, USA, 2003.

[10] D. J. Collins, "Damage detection in composite materials using acoustic emission and self-sensing fiber", Department of Metallurgy and Materials School of Engineering, University of Birmingham, 2009.

[11] R. N. Swamy, "New Reinforced Concrete, Concrete Technology \& Design", Surrey University Press, 1984.

[12] D. J. Hannant, "Fiber Cement \& Fiber Concretes", Wiley Inter Science Publishing, 1978.

[13] A. Kumar, A. Srivastava, "Preparation and Mechanical Properties of Jute Fiber Reinforced Epoxy Composites", Industrial Engineering \& Management, 06 , 4, 2017.

[14] M. Ramesh, K. Palanikumar, K. H. Reddy, "Comparative Evaluation on Properties of Hybrid Glass Fiber- Sisal/Jute Reinforced Epoxy Composites", Procedia Engineering, 51, $745-750,2013$. 